\title{
Los bienes comunes intangibles en el capitalismo cognitivo
}

\author{
The intangible commons in cognitive capitalism
}

\author{
ÁLVARO RAMIS \\ Pontificia Universidad Católica de Chile \& Universidad de Valencia
}

Artículo recibido: 30 junio 2013

Solicitud de revisión: 09 octubre 2013

Artículo aceptado: 23 octubre 2013

\section{Resumen}

Este texto analizará críticamente la actual fase económica para mostrar la importancia de los bienes comunes intangibles. Sondea la tesis de un nuevo modo de producción en ciernes, basado en la gestión colaborativa. Analiza los intangibles de acuerdo a su calidad y carácter. Compara los sistemas de patentes y derechos de propiedad intelectual que permiten su apropiación y las resistencias a su "comoditización» desde el software libre y las propuestas de flexibilización de derechos de autor. Advierte sobre el «fetichismo tecnológico» y propone un marco mínimo de discernimiento en dilemas vinculados a estas materias.

Palabras clave: Bienes Comunes, Intangibles, Propiedad intelectual, Mercantilización.

\begin{abstract}
It will scan critically the current economic phase to show the importance of the intangible commons. Investigate the thesis of a new mode of production based on collaborative knowledge management. Analyze the specificities of the intangible commons according to their quality and character. We will compare the patent and intellectual property rights that allow its appropriation. Study the resistance to its «commoditization» from the free software paradigm and the proposed relaxation of copyright. Warn of the risks of new forms of «technological fetishism» and conclude by proposing a minimum framework of discernment dilemmas in these matters.
\end{abstract}

Keywords: Commons, Intangibles, Intellectual property, Commodification. 


\section{LA PRODUCCIÓN PEER-TO-PEER A DEBATE}

En 1967 John Kenneth Galbraith describió un proceso de concentración de la economía norteamericana junto a un desarrollo exponencial de la tecnología y de la financiarización. Advirtió una reducción de los sindicatos y del estado y el advenimiento de una «tecno-estructura» que tendería a concentrar decisiones. Touraine (1969), Drucker (1968), Tofler (1973) y Bell (1976) van a explorar este cambio bajo la idea de «sociedad postindustrial».

Es el tránsito entre un paradigma «fordista-taylorista», enmarcado en la escuela keynesiana, hacia un paradigma tecno-económico "post-fordistatoyotista», enmarcado en la escuela monetarista de Chicago (Coriat, 1992). Este nuevo modelo impulsa la productividad con un sistema integrado de gestión que abandona la cadena en serie para reemplazarla por la desconcentración productiva. Supera la integración vertical u horizontal fordista mediante trabajadores polivalentes, tecnología multifuncional para la producción simultánea de varios productos (Just in time) y una «línea de arranque» en reemplazo de la tradicional «línea de empuje».

Las economías «de escala», que buscaban la eficiencia por el lado de la oferta, graduando sus escalas de producción de un tipo único de producto, dejan paso a las economías «de gama», que logran eficiencia graduando la demanda por marketing y distribución de diferentes productos. Se crean puestos de trabajo especializados, aumenta el área de servicios, se feminiza la mano de obra, y en los análisis socio-económicos se privilegian las tipologías de nivel de consumo por sobre de la clase social. Se subjetivizan los vínculos con las mercancías, perfeccionando el trabajo relacional y comunicativo para interpretar a los deseos y valoraciones. Adquiere centralidad el control de la información y el conocimiento que potencialmente puede añadir valor agregado.

El nuevo paradigma «post-fordista-toyotista» presupuso un reconocimiento de los factores comunicativos a nivel productivo. Masuda (1984) vaticinó acertadamente que las innovaciones computacionales incrementarían la productividad exponencialmente. Para ello se perfeccionó la gestión de la información y los flujos de comunicación. Hoy se demanda cada vez más la opinión de los operarios en el proceso de mejora continua, teniendo en cuenta sus sugerencias en el ámbito del control de calidad. Pero simultáneamente sus condiciones contractuales se deterioraron, al extenderse de forma abusiva los mecanismos de subcontratación. 
De allí que algunos especialistas observen la emergencia de un nuevo modo de producción, en fase germinal, al que llaman peer-to-peer ( $\mathrm{P} 2 \mathrm{P}$ ). Perceptible en el ámbito de la información y la industria cultural, sería potencialmente extendible a la provisión de otros servicios y de bienes materiales. Benkler (2006) ha teorizado sobre una Commons-based peer production. Bauwens se ha centrado en «La economía política de la producción de pares» (2005). Ricci y Wiese (2011) han investigado la consolidación de un «imperativo de la colaboración» en el ámbito empresarial. Gutiérrez-Rubí y Freire hablan de «empresa crowd» (2013). Se extienden neologismos como: crowdfunding, crowdthinking, crowdcuration, crowdcreating, coworking que muestran que la reciprocidad adquiere centralidad en los sectores más innovadores de la economía.

Kelly en New Rules for the New Economy (1998) sostuvo que en el nuevo contexto tecnológico la riqueza se tiende a derivar directamente de la innovación, y no de la optimización. El proceso económico se orientaría a "apoderarse de manera imperfecta de lo desconocido", lo que puede implicar que «el ciclo de encontrar, nutrir y destruir ocurre más rápido y con más intensidad que nunca» (Kelly, 1998: 21). La incorporación masiva de la alta tecnología subordina el problema de la productividad al de la pertinencia, propio de la era "postfordista». El dilema no es producir más rápido sino saber exactamente "qué producir». La línea de producción unidireccional se transforma en el cuello de botella económico. Para captar las áreas con valor agregado es necesario recurrir a las «multitudes inteligentes» (Rheingold, 2002).

Bauwens considera que el cambio de paradigma tecno-productivo permite producir valores de uso directamente, fuera del control del mercado, «post-capitalistamente» en la medida en que su reproducción no se basa en el capital sino en una infraestructura basada en redes distribuidas. La producción «entre pares» representaría un tercer modo de producción, auto-organizado, sobre la base de una amplia diversidad de pequeños grupos o individuos que configuran una jerarquía de coordinación que parte desde abajo. Es un modelo que no busca abolir el mercado sino que lo subsume como un subsistema, asignando recursos de acuerdo al criterio de precios. Tampoco busca abrogar al Estado, sino que lo reubica como un socio en la generación de una infraestructura de participación. Siguiendo a Cosma Orsi, sería un «estado-socio» como «una forma de Estado que permite y facilita la creación de valor social por parte de sus ciudadanos» (Bauwens, 4 marzo 2012). Este estado «crea el entorno adecuado y la infraestructura de apoyo para que los ciudadanos pueden aportar valor median- 
te el trabajo $\mathrm{P} 2 \mathrm{P}$ del cual se beneficia la sociedad en su conjunto» (Bauwens, 4 marzo 2012). Lo público se reenfoca, desde la provisión directa de los bienes y servicios a la provisión de una infraestructura institucional que permite la cooperación, protegiendo los bienes comunes y facilitando a los ciudadanos su acción auto-organizada. Este enfoque sería coherente con la creciente conciencia del origen colectivo de la creatividad, lejos de la creatio ex nibilo.

Esta economía peer to peer permite a Bauwens pensar en tres modelos de negocios basados en la producción colectiva: share economy, commons economy y crowdsourcing economy. Share economy comprendería plataformas participativas para la expresión creativa, como You Tube. Esta participación no se cobra ni se remunera, pero los propietarios de las plataformas ofertan servicios complementarios y espacios publicitarios. Por commons economy, Bauwens entiende comunidades que producen «artefactos comunes» disponibles bajo régimen común, como es el caso del software libre. En torno a estos artefactos se genera un ecosistema de negocios, basado en empresas de servicios con valor agregado. Linux sería el modelo paradigmático. Finalmente crowdsourcing economy supone implicar a una audiencia (universal o particular) en su cadena de valor. Bajo la lógica del crowdsourcing operan plataformas como Choosa, Twago. Este modelo se vincula a los conceptos de crowdfunding -financiación colectiva o micromecenazgo-, crowdcreation -especialmente en arquitectura, urbanismo y diseño- crowdvoting -convocatoria a una votación para validar una idea en el mercado- o crowdwisdom -incorporar de forma integral el conocimiento de los clientes.

\section{EL ACERCAMIENTO DE LOS COMUNES INTANGIBLES}

La «economía del conocimiento» enfrenta un dilema crucial dada la dimensión inmaterial de sus mercancías, clave de la rentabilidad en la sociedad postindustrial. Esta esfera no es apropiable y mercantilizable per se. Polanyi (1997:122) advirtió que ello exigía una ficción técnico-jurídica que permitiera disfrazar de mercancía aspectos del producto, reservando derechos exclusivos. "No obstante este disfraz no cambia nada a la realidad de bien común del bien así disfrazado» (Gorz, 7 enero 2008).

En la fase «fordista» los conocimientos asociados a los medios de producción, como diseños de máquinas y tecnologías, se podían monopolizar ya que eran inseparables del bien material que los contenía. La innovación 
era un componente más del "capital constante». En la fase "postfordista», los bienes inmateriales se pueden desvincular de cualquier objeto o persona que los contenga, ya que «acceden a una existencia independiente de todo uso particular y se convierten en susceptibles de ser reproducidos en cantidades ilimitadas por un coste ínfimo, tras su traducción en programas» (Gorz, 7 enero 2008). La digitalización hace posible su masificación transformándolos en bienes abundantes, de disponibilidad ilimitada y común, en la medida en que permanezcan bajo el dominio público.

Un signo inmaterial se puede convertir en mercancía si se puede objetivar, circular, intercambiar y vender, "por lo que el trabajo inmaterial no es solamente fuente de productividad, sino también en sí mismo trabajo productivo» (Blondeau, 2004: 33). Pero se trata de una conversión necesariamente provisoria e incompleta de un «bien común disfrazado [...] cuyo acceso y uso libres están prohibidos porque permanecen siempre posibles» (Gorz, 7 enero 2008). Quienes poseen el dominio de un bien inmaterial sólo pueden vender mediante patentes y copyrights los derechos de acceso o de uso «bajo licencia» pero no pueden vender, aunque lo deseen, la propiedad misma del bien intangible tal como se haría con una verdadera mercancía. Gorz concluye así que «la economía del conocimiento» se basa en la apropiación de una riqueza cuya vocación es la de ser un bien común:

Todo lo que se traduce en lenguaje numérico y reproducible, comunicable sin gastos tiende irresistiblemente a convertirse en un bien común, incluso en un bien común universal cuando es accesible a todos y utilizable por todos. Cualquiera puede reproducir con su ordenador contenidos inmateriales como el diseño, planes de construcción o de montaje, fórmulas y ecuaciones químicas; inventar sus propios estilos y formas; imprimir textos, grabar discos, reproducir tablas. (Gorz, 7 enero 2008).

En una economía basada en el conocimiento como innovación productiva radicaría una contradicción, entre los rasgos rentistas que aspiran a medrar sobre los derechos de propiedad intelectual y los aspectos creativos e innovadores que le caracterizan de suyo, que demandan colaboración, cooperación y construcción de espacios de dominio compartido. Esta contradicción adquiere centralidad en la medida en que la preeminencia del «individualismo posesivo» (Macpherson, 2005) puede secar las fuentes de riqueza. Hardt y Negri observan una paradoja:

La producción social y económica contemporánea tiene un carácter cada vez más común, que desafía y excede los límites de la propiedad (privada). La capacidad de capital para general ganancia está disminuyendo, como resultado de la pérdida de su capacidad em- 
presarial y de poder administrar disciplina y cooperación social. Por el contrario, el capital acumula cada vez más riqueza principalmente por medio de formas de renta, casi siempre organizadas mediante instrumentos financieros, a través de los cuales captura valor que es producido socialmente y con independencia de su poder. Pero toda instancia de acumulación privada reduce la potencia y la productividad de los bienes comunes. De esta suerte la propiedad privada se está convirtiendo no sólo en un parásito, sino también en un obstáculo para la producción y el bienestar social. (Hardt-Negri, 2011: 6)

La producción inmaterial tiende adquirir un carácter cada vez más común, por lo que desafía y excede los límites de la propiedad privada y estatal. En el ámbito de las redes telemáticas este proceso es evidente, se observa que la gestión colaborativa constituye una estrategia que fortalece la capacidad innovadora, gracias a una administración basada en la autoregulación de unidades autónomas vinculadas por mecanismos eficientes de cooperación social. Sin embargo, esta posibilidad entra en contradicción con las tendencias rentistas. Lo que parece surgir es una producción basada en colaboración, redes sociales, lo que exige una economía del don basada en la libre disposición de tiempo y creatividad, pero que también demanda la proliferación de contratos no vinculantes que operan fuera del mercado formal.

\section{LA ESPECIFICIDAD DE LOS BIENES COMUNES INMATERIALES}

Comprender los bienes comunes intangibles exige un acercamiento específico. Vercelli y Thomas han propuesto una clasificación general según «calidad» $\mathrm{y}$ «carácter» que parte de una definición genérica de bienes como «todo aquello que tiene -o puede tener- un valor, un interés, una utilidad, un mérito» (2008: 53) y que consecuentemente puede ser objeto de derecho, y protegido jurídicamente. La «calidad» de los bienes apunta a las características o propiedades constitutivas, su composición elemental. Podemos distinguir entre bienes materiales -o tangibles- y de bienes intangibles -inmateriales, culturales, intelectuales, del ingenio o del espíritu humano.

Los bienes materiales son objetos tangibles del mundo físico, en cambio los intangibles son las ideas, costumbres, conocimientos, creencias, lenguajes, tradiciones, saberes, formas de expresión, artes, o técnicas genéricamente abstractas, dinámicas y se encuentran dispersos. Mientras los bienes materiales son limitados, finitos, agotables, en competencia y escasos, los intangibles se presentan ilimitados, infinitos, inagotables, no consumibles, no devastados, no contradictorios entre sí y basados en la abundancia. La 
distinción entre bienes materiales e inmateriales no siempre es clara. Las nuevas tecnologías digitales, los avances en inteligencias artificial, biotecnología o nanotecnología complejizan la definición de la «calidad» de los bienes, con consecuencias en el plano legal, ya que algunos bienes materiales incluyen también a aquellos objetos que actúan como soporte del trabajo intelectual. La diferencia entre el libro, como objeto material, y el bien intelectual que contiene parece evidente. Pero esta distinción es más borrosa en un programa informático o una secuencia cromosómica.

La diferencia por «calidad» se complementa con el «carácter» de los bienes, una característica que complementa la «calidad» y que determina a los dueños o titulares del bien, delimitando el modo como se administra. El «carácter» apunta a las regulaciones legales, pertinentes a un bien específico. En lo jurídico se tiende a considerar el carácter como un indicador de la relación de un objeto con las personas naturales o jurídicas, comprendidas como dueños, titulares, poseedores, tenedores, usuarios, etc. El «carácter» da cuenta de las circunstancias, formas o estilos distintivos de propiedad y de uso que le son propios y que distinguen a un bien de otros. Un mismo bien puede estar en relación con un individuo en carácter de propiedad, usufructo, dominio, alquiler, etc.

El «carácter» de los bienes funciona de forma diferente si se aplica a los materiales o a los inmateriales. La regulación de los materiales arraiga en la tradición del derecho romano que hizo según el régimen de «propiedad/ dominio» o «derechos reales», que otorga al titular plena potestad para usar, gozar o disponer del objeto según su voluntad, con mayores o menores limitaciones dependiendo de la legislación, y faculta para excluir a terceros de la relación con el bien. Sólo contempla la copropiedad o condominio cuando existe pluralidad de titulares sobre las partes indivisas de una misma cosa. En cambio los bienes intelectuales se han regulado jurídicamente de acuerdo a la tradición moderna que aplica el régimen de los «derechos intelectuales», que se caracteriza por poseer «mayor heterogeneidad, diversidad y dinamismo que el sistema de la propiedad/dominio de los bienes materiales» (Helfrich: 2008, 56). Estos derechos se expresan históricamente de dos maneras: como propiedad industrial y como derechos de autor.

El diferente régimen de protección jurídica que se aplica a bienes materiales e inmateriales presupone que estos últimos, en stictu sensu, no son apropiables. A diferencia del régimen de derechos de propiedad material, los derechos intelectuales son limitados en el tiempo y no son excluyentes, debido a que el sistema de los derechos intelectuales busca el equilibrio entre los intereses de los creadores y la comunidad, tendiendo a la distri- 
bución de los bienes intelectuales pero a costa de mantener cierta incertidumbre en su carácter. El régimen de propiedad o dominio material tiende a garantizar la certeza jurídica del «carácter» del bien, pero a costa de una mayor concentración de su propiedad.

Esta diferencia es más clara si analizamos el régimen de propiedad. Los bienes materiales pueden tener tres tipos de carácter: Privados, cuando tienen un dueño, ya sea una persona física o jurídica, o un estado, en cuanto titular exclusivo de sus derechos. Público, cuando están bajo titularidad de un estado, o de las administraciones subnacionales o municipales, y se consideran como pertenecientes a toda la comunidad. Su destino es el uso público, pero el ejercicio de los derechos sobre ellos está sujeto a la reglamentación gubernamental que los administra.Y común, cuando se encuentran en situación de comunidad de propietarios. Los intelectuales se pueden regular con carácter privativo, público o común. Pero este tipo de bienes se presentan como ilimitados, infinitos, inagotables, no consumibles, no devastados, no contradictorios y abundantes. Se hace mucho más flexible la administración de los derechos del autor, productor o inventor del bien determinado. Es posible implementar sub-categorías que gradúen la reserva o liberación de los derechos de autor o patentes industriales.

Se puede hablar de propiedad intelectual e industrial a partir del siglo XVIII, coincidiendo con el influjo lockeano (Sábada, 2008: 54). Con anterioridad las regulaciones y derechos exclusivos tenían carácter gremial o estamental, y garantizaban los monopolios corporativos de artesanos especializados o de la casta sacerdotal. La imprenta supuso un reto al control de la información y el conocimiento, que el absolutismo trató de restringir por mecanismos legales. Solamente con el advenimiento del primer capitalismo liberal y de las revoluciones inglesa y francesa se va a consolidar un paradigma «autor/inventor» que dominará hasta la actualidad.

Los derechos de propiedad intelectual e industrial han pasado por cuatro fases: inglesa, francesa, americana y global (Sábada, 2008) que muestra la conformación de un «cuasi-mercado» de las ideas, evolucionando en paralelo a la consolidación de la protección legal de los bienes tangibles. En la fase inglesa se produjo un primer contrato social sobre el conocimiento, por el cual se aceptaban restricciones a la libre reproducción de impresos a cambio de una difusión mucho más rápida.Y el estado aumentó su capacidad de control y censura (Busaniche, 2007:16). La fase francesa buscó que las patentes y el derecho de autor garantizaran a inventores y autores el control sobre sus obras, y que gozaran de un incentivo a la creación independiente de la voluntad de editores, mecenas o gobiernos. Se compren- 
día que ello operaba bajo la forma de un privilegio o monopolio temporal, y en ningún caso bajo la idea de propiedad en el sentido jurídico y perpetuo del término (Attali, 1989: 290). La fase americana trata de armonizar el interés del autor o inventor, afirmado en la fase francesa, con el fin o destino social de sus obras. Se privilegiará a quienes patenten las obras por sobre los autores materiales efectivos, y a los financistas o productores por sobre los investigadores o creadores. Estos criterios respondían, en su origen, al afán de Jefferson y los constitucionalistas americanos por hacer del sistema de patentes y copyright un acicate de la innovación en artes y ciencias en tanto motor de desarrollo económico. Este productivismo se exacerbará bajo el modelo «fordista» por la judicialización de la explotación comercial de patentes, conformando un capitalismo monopolista que crecientemente sustituirá la libre competencia por la disputa acotada entre oligopolios.

La universalización de la fase americana en la actual fase global, abarca todos los ámbitos sujetos a potenciales intercambios comerciales. Es el tránsito definitivo de la patente o del derecho de autor como incentivo o protección del creador y su obra al monopolio rentista de un conglomerado corporativo. La ampliación del espectro de lo patentable incluye funciones y algoritmos matemáticos, biotecnologías, vida orgánica y tecnologías digitales. Se incentivan acuerdos vinculantes entre los estados que internacionalizan las normas referidas a copyright, marcas registradas, patentes, diseños industriales, denominaciones de origen. Los litigios pasan de la esfera del derecho civil o comercial al derecho penal (Busaniche, 2007:18). El dominio público se ve progresivamente delimitado y acotado: constituye un bien común, la herencia cultural de la humanidad, y está bajo la permanente amenaza de nuevos monopolios (Busaniche 2007, 23).

La reproducción técnica de la obra intelectual impone nuevas tensiones aparejadas al cambio tecnológico. Mientras se necesitó de cierta capacidad industrial para reproducir las ideas, el control de las copias y reproducciones ilegales se ejerció con facilidad. Pero bajo la nueva reproductibilidad digital, a un costo marginal, casi nulo, sin pérdida de calidad ni problemas de economía de escala, se han abierto dilemas relevantes al derecho social a reproducir el conocimiento. 


\section{EL SOFTWARE LIBRE Y LAS «CUATRO LIBERTADES»}

En reacción a la inflación normativa de los derechos de propiedad intelectual y patentes industriales, surgió un movimiento que demanda la preservación de los bienes comunes intangibles y las libertades en el ámbito de la reproducción del conocimiento. Se ha originado en el campo de la programación y el desarrollo de nuevos sistemas operativos y sus aplicaciones. Un punto de partida fue la publicación del Manifiesto GNU (Stallman, marzo 1985) que supuso el rechazo explícito al cercamiento del código fuente del software, sacándolo del dominio público.

Stallman propuso un sistema operativo que garantizara el total «control en el uso» a los usuarios de la informática: «un buen sistema de software tan libre como el aire» (Stallman, marzo 1985). Así todo el equipamiento lógico podría ofrecer a los usuarios cuatro libertades fundamentales: de uso, de estudio, de distribución y de modificación. El manifiesto GNU sostiene que estas libertades están amenazadas debido a la hegemonía del software privativo, que impone cercos a los derechos de uso.Y a la vez que las restricciones propietarias, lejos de promover los avances y proteger a los creadores, obstaculizan el desarrollo de la tecnología. Las restricciones propietarias sobre el software atacan la solidaridad social, elemento fundante en la configuración de los sistemas informáticos. Su argumento remite al principio de autonomía ante la posible posición monopólica del programador. Garantizar el libre acceso al código fuente permite a los usuarios cambiar o adaptar el sistema informático. También remite a la necesidad de reducir costes de acceso al software, eliminando las barreras de entrada que operan mediante royaltys. En contrapartida, para mantener el soporte lógico bajo dominio público, evitando el riesgo de sea apropiado ilegítimamente, ha impulsado la creación de licencias de código abierto que permiten explícitamente a los usuarios el acceso completo al código informático del software. Estas licencias permiten la utilización, copia, modificación y redistribución de la obra o trabajo a las que se aplican y simultáneamente garantizan para cualquier receptor una copia o una versión derivada. Hoy existe una infinidad de licencias libres que gradúan de distintas formas los derechos que reservan, siendo la más conocida Creative Commons impulsada desde 2001 por Lessig (2006).

El software libre supone un quiebre epistemológico que va más allá de la industria informática ya que desafía el paradigma de licencias comerciales y patentes basadas en el «individualismo posesivo». Stallman ejemplifica recordando que la industria del software no necesitó de patentes para su 
desarrollo, ya que estas no se reconocieron legalmente hasta 1982 y no tuvieron un efecto real en la regulación hasta 1990, un momento en el que estaba consolidada la base empresarial en este campo. Para Stallman la idea que de las patentes de software se benefician los desarrolladores de software es una comprensión errónea del sistema de patentes. Se observa un continuo proceso de parálisis de la innovación, por la judicialización perpetua por supuestas violaciones de patentes por «entidades no practicantes» (ENP), propietarias legales de una patente que no fabrican ni utilizan, que interponen acciones judiciales para obtener compensaciones económicas de los verdaderos fabricantes del producto.

Esta industria intangible es una innovación disruptiva con los modelos tradicionales, ya que por su funcionamiento compatibiliza de forma eficiente la sostenibilidad económica y la libertad de los usuarios, desconcentrando la oferta. Impugna la fase global del régimen de propiedad intelectual, ofreciendo una alternativa en el marco del mercado, que se comprende mediante la distinción de Ostrom entre "propietarios» de un sistema de recursos y «apropiadores» de unidades de recursos (Ostrom, 2002: 2). El software libre, como recurso de acervo común, permite que diferentes «apropiadores» exploten las unidades de recurso, sin excluir y sin que el software mismo esté en manos de uno en particular. Bauwens ha identificado en el funcionamiento de la industria del software libre una interacción permanente de tres actores que actúan coordinadamente a lo largo del proceso productivo:

Una comunidad de colaboradores que crean un patrimonio común del conocimiento, software o diseño; una coalición emprendedora que crea valor de mercado en la parte superior de ese patrimonio común, y un conjunto de «instituciones con fines de lucro» que gestionan la forma en que esta cooperación se lleva a cabo. (Bauwens, 4 marzo 2012).

La comunidad de programadores, observa Bauwens, no funciona sólo desde criterios participativos, sino valorizando la experiencia, con la lógica poliárquica que ha teorizado Ostrom en la gestión de los bienes comunes tangibles. Los criterios de asignación no pasan por la democracia -como decisión de todos los involucrados-, o del mercado -sistema de precios- o de jerarquía -autoridad superior. Estos criterios serían modos de asignación propios de sistemas basados en recursos escasos. Pero en el caso de la industria del software libre el recurso productivo es bien abundante e inmaterial -conocimiento, código, diseños- por lo que puede ser objeto de reproductibilidad infinita, a un costo marginal. 
En la producción entre pares la clave es el principio de orientación al objetivo, el cual impulsa mecanismos de cooperación y autoorganización entre las partes, asignando tareas de forma descentralizada e indirecta (Pekka; et al., 2002). Bauwens califica estos mecanismos de «estigmérgicos», una categoría trasladada del campo biológico que describe el comportamiento de los insectos sociales, que establecen mecanismos de cooperación por medio de señales -por ejemplo mediante trazos de feromonas en el caso de las hormigas. La estigmergia explicaría la colaboración eficiente entre agentes simples, carentes de memoria, inteligencia y autoconciencia. Los rastros señaléticos que los insectos depositan en el medio ambiente estimulan en sus pares una acción subsiguiente que adquiere coherencia en función del objetivo general que se ha buscado. Una idea seminal depositada en un espacio abierto atrae a otros agentes que la aprovechan y modifican, hasta que con el paso del tiempo se convierte en una compleja estructura basada en aportes interconectados, sin necesidad de planificación, control, o incluso comunicación directa entre los involucrados.

\section{LOS PELIGROS DEL «CIBERFETICHISMO»}

Este modelo productivo, basado en la gestión colaborativa -peer to peer- de los bienes intangibles ¿es poseedor de virtudes económicas y políticas específicas? Este postulado es objeto de críticas económicas, políticas y éticas, porque la producción de bienes materiales sigue siendo la base de la economía, aunque los procesos de deslocalización y desindustrialización la hayan hecho menos visible. Las materias primas y la producción industrial no han perdido centralidad, ya que las necesidades básicas siempre reclaman su satisfacción por medio de bienes tangibles. Internet, presentada cotidianamente como un espacio inmaterial en el que solamente fluyen algoritmos, no se puede concebir sin sus soportes materiales en una infraestructura de data centers, cables submarinos, antenas y repetidoras telefónicas que cubren literalmente todo el planeta.

La sociedad postindustrial se suele idealizar como un futuro inexorablemente democrático y humanizador, sin advertir su impacto en áreas sensibles, como la precarización del empleo, el incremento del paro y el sobreapalancamiento financiero. Economistas «neo-schumpeterianos», como Pérez Reverte y Freeman lo explican en el marco del desplazamiento entre la «cuarta onda» de Kondratiev a la «quinta onda», que estaría centrada en el dominio de las tecnologías de información y la comunicación. Al recurrir a 
los ciclos Kondratiev, esta escuela incorpora al análisis las fluctuaciones cíclicas de la economía capitalista, que atraviesa regularmente por etapas sinusoides de cincuenta o sesenta años, en los que se alternan períodos de alto crecimiento para luego pasar por depresiones prolongadas. Constatan que en los ciclos contractivos se genera una tendencia en el capital a refugiarse en áreas financieras especulativas, que ocasionan una pérdida en la noción del valor real de los bienes (Pérez, 2002: 75).

La «escuela de la regulación» advierte que el paradigma fordista concilió crecimiento regular y el aumento salarial al menos en los países industrializados. Ello requería una producción masiva, un reparto proporcional del valor añadido entre capital y trabajo y un pacto de estabilidad y rentabilidad empresarial, garantizando la plena capacidad industrial, en la búsqueda del pleno empleo. Esto es imposible de mantener bajo el paradigma «postfordista-toyotista» (Aglietta, 1998). Gorz sostiene que la principal causa de la actual crisis financiera y económica no radica en la persistencia de patrones productivos anticuados sino en los violentos cambios tecno-científicos de las últimas décadas. Mientras más aumenta la productividad, más difícil se hace mantener el volumen de utilidades:

La informatización y la robotización han permitido producir cada vez más mercancías con cada vez menos trabajo. El coste del trabajo por unidad de producto no ha dejado de disminuir y el precio de los productos tiende a bajar. Sin embargo, cuanto más disminuye la cantidad de trabajo para una producción particular, más tiene que aumentar el valor producido por trabajador -su productividad- para que la masa de beneficio no disminuya. Obtenemos por tanto esta paradoja aparente: cuanto más aumenta la productividad, más tiene que aumentar ésta para evitar que el volumen de beneficio disminuya. La carrera hacia la productividad tiende a acelerarse, los recursos humanos a reducirse, la presión sobre el personal a endurecerse, el nivel y la masa salarial a disminuir. El sistema evoluciona hacia un límite interno donde la producción y la inversión en la producción dejan de ser lo suficiente rentables (Gorz, 7 enero 2008).

La sobre-financiarización de la economía se explicaría porque la producción no logra valorizar los capitales acumulados, ya que una parte cada vez más considerable permanece como capital especulativo, en la forma de ventas de bienes futuros o endeudamiento. La informatización y automatización, al reducir el coste de producción y los precios de las mercancías motivaría a sustraer los productos de las leyes del mercado, confiriéndoles cualidades inmateriales que compensen su abaratamiento. Los precios dependen cada vez más de cualidades intangibles, alejadas del valor de uso. Los atributos inmateriales buscan otorgar a los bienes de consumo un estatus similar al de las obras de arte, mediante la adscripción a criterios de estilo, novedad, prestigio, marca o exclusividad. Así el productor logra un 
grado de monopolio en su producción y una renta que compensa la reducción de costes, para lo cual necesita prolongar en el tiempo los derechos de propiedad intelectual, amortizando la inversión en innovación.

Para Morozov (2012) este cambio tecno-productivo impulsa tendencias al «ciberfetichismo» que sobreestimaría sus impactos positivos. Morozov denuncia el «ciberutopismo» y el «Internet-centrismo» como discursos ingenuos e irresponsables que no perciben la censura, propaganda y vigilancia que se incuban al interior de las redes telemáticas. Mattelart (1974) ya lo analizó al sostener que la nueva capacidad de estas tecnologías va aparejada a una nueva forma de «sociedad del control», que lejos de democratizar y personalizar las relaciones económicas, las fragmenta y masifica. Mattelart califica el concepto de «sociedad de la información» como un paradigma tecnoutópico, que sobreestima la nueva techné instrumental y estadística, olvidando los aspectos teleológicos inherentes a ella.

Tras el modo de producción peer to peer se evidenciarían formas de determinismo tecnológico, verdaderos subproductos de la concepción mercantil de los vínculos sociales. Las posibilidades de vinculación social vía telemática no estarían adecuadamente ponderadas: «Es como si creyeran que Internet nos permite reengancharnos con el entorno supuestamente cordial de las sociedades tradicionales tras el incómodo paréntesis de la modernidad» (Rendueles, 13 mayo 2013). Se propondría una falsa analogía conceptual entre las formas históricas de cooperación que han sostenido el cuidado y administración de los bienes comunes materiales y las nuevas formas de cooperación que permiten la gestión de los bienes intangibles. Pero las propias investigaciones de Ostrom, sostiene Rondueles, mostrarían que las condiciones institucionales que hicieron posibles los acuerdos sociales para preservar los recursos de uso común en el tiempo supusieron un complejo entramado organizativo, que requirió una larga deliberación que se logró incrustar el proceso productivo, por medio de reglas sociales estables que exigen un férreo compromiso con ellas.

La analogía entre los enclosures de tierras comunes y las actuales restricciones a la libre circulación de la información no tendría fundamento. A su juicio los bienes comunes digitales carecerían de las características generales que Elinor Ostrom atribuye a los commons: «no tienen límites bien definidos, las reglas de apropiación y provisión no están adaptadas al entorno local, no hay mecanismos eficaces de vigilancia y resolución de conflictos» (Rendueles, 13 mayo 2013) Los recursos de uso común digitales serían en realidad «bienes públicos puros», ya que poseen baja rivalidad y son de difícil exclusión al ser reproducibles sin coste adicional. Estos 
argumentos se entroncan con la denuncia de la «ideología californiana» (Barbrook y Cameron, 1996) que describió tendencias "ciberfetichistas» presentes en California a fines de los años 90 e inicios del 2000. Se trataría de «una forma optimista y emancipatoria de determinismo tecnológico» (Barbrook y Cameron, 1996) que idealizaría las formas de producción postindustriales basadas en la información, confiriéndoles una capacidad natural de impulsar el crecimiento, el empleo y reducir las estructuras de poder del Estado, favoreciendo comunidades virtuales. La «Ideología Californiana» espera que la tecnología de la información liberará al género humano de toda forma de control político, haciendo posible la plena autonomía individual y abriría un campo de riqueza inexplorado que permitiría a quienes desarrollen sus capacidades competir de forma equitativa en un «mercado liberado» de las asimetrías y barreras de entrada instaladas por los oligopolios. Pero el surgimiento de las nuevas tecnologías también implica que las transnacionales y los Estados puede manejar una enorme cantidad de información personal, sin controles. Lejos de contribuir a la libertad individual, construyen un sistema global controlado por una rígida lógica corporativa-estatal que no se podría desafiar o cambiar (National Intelligence Council, 2012).

Lejos de contribuir a la cohesión y equidad social, muchas experiencias económicas al alero de las nuevas tecnologías exacerbarían la estratificación social y la precariedad en el empleo, por medio del teletrabajo y otras formas de externalización de tareas. Procesos como el crowdsourcing explotarían indirectamente el trabajo de los individuos (Estellés, 2011). De allí que Barbrook (2007) identifique nuevas clases y estratificaciones sociales producto de la economía del conocimiento, por medio de los acrónimos y neologismos que encuentra en el habla cotidiana: netizens, elancers, cognitarians, swarm-capitalists, hackers, produsumers, knowledge workers, pro-ams. Berardi (2003:34) ha acuñado el concepto de "cognitariado» para referirse a los trabajadores de las tecnologías y manipuladores de signos: «El cognitariado es el área productiva de los que elaboran, crean y hacen circular los interfaces tecno-lingüísticos, tecno-sociales, tecnomédicos, etc., que inervan cada vez más profundamente la sociedad contemporánea.». Huws (2003) utiliza a expresión «cibertariado» para describir cómo en los países capitalistas avanzados la flexibilidad y precariedad laboral están vinculadas a la nueva tecnología en la medida en que estos nuevos productos facilitan la producción freelance y el outsourcing. Los trabajadores más precarizados están ahora obligados a pagar por las herramientas de su oficio y a trabajar en forma aislada de cualquier compañero. El traba- 
jo intangible exige el disciplinamiento biopolítico de los cuerpos tangibles de unos trabajadores cuya labor acontece predominantemente en su mente. La valorización del capital se liga cada vez más al dominio biopolítico de las condiciones sociales de la producción y a la capacidad de transformar en «mercancías ficticias» (Polanyi, 1989: 117).

Virno (2003a) advierte el primado de una «actividad sin obra», basada en la combinación de experiencia tecnológica e inteligencia social, que puede ser comprendida con la categoría marxiana de general intellect. De acuerdo con el «fragmento sobre las máquinas» de los Grundrisse, la tecnología productiva es «fuerza objetivada del conocimiento», por medio de la cual se actualizan las facultades generales del espíritu humano: el lenguaje, las capacidades de aprendizaje y abstracción, las posibilidades de relación conceptual y los procesos de autorreflexión. Marx parece intuir que la capacidad de concierto del intelecto humano sería el factor determinante de la productividad en la era tecnológica El general intellect hace inteligible las formas materiales de los objetos físicos y de esa forma permite «El devenir cosa de un pensamiento: eso es una abstracción» (Virno, 2003b: 65).

\footnotetext{
El desarrollo del capital fijo revela hasta qué punto el conocimiento o knowledge social general se ha convertido en fuerza productiva inmediata, y, por lo tanto, hasta qué punto las condiciones del proceso de la vida social misma han entrado bajo los controles del general intellect y remodeladas conforme al mismo. Hasta qué punto las fuerzas productivas sociales son producidas no sólo en la forma del conocimiento, sino como órganos inmediatos de la práctica social, del proceso vital real (Marx, 1967: 230)
}

Estas miradas escépticas de la sociedad post-industrial y de la información han llevado a proponer una categoría explicativa distinta bajo la idea de capitalismo cognitivo (Blondeau et al., 2004). Acentúa los aspectos contradictorios de esas transformaciones, al sostener que en la fase actual la creación, tratamiento y transmisión de la información se han convertido en una fuente central de productividad y poder para las empresas. Los bienes intangibles, que la tradición marxista denominaba «indirectamente productivos», ocupan hoy un rol central en la productividad. Ya que el área de los servicios bajo el sistema de producción postfordista es el modo generalizado de trabajo asalariado, con las nuevas tecnologías el trabajador pasa a ser también producto y herramienta, objeto e instrumento de trabajo a un mismo tiempo.

Lebert y Varcellone (2010) observan un nuevo diseño de la división internacional del trabajo, orientado a que los países del «Norte global»se centren a gran escala en la producción de bienes inmateriales, ligados al conocimiento, obteniendo utilidades de los derechos de propiedad intelec- 
tual, mientras los países del «Sur global» se concentran en la producción de los bienes materiales y en proveer recursos no renovables y materias primas. Bajo el "capitalismo cognitivo» la creación de valor y la competitividad estarían basadas en la capacidad de innovación y creatividad, pero con la condición de «financiarizar» esos nuevos bienes inmateriales de modo que constituyan el núcleo de una renta. Se hace necesario un nuevo tipo de enclosure, ya no sobre la tierra o los bienes materiales, sino sobre los bienes intangibles, de forma que sea posible capitalizar los dividendos de los derechos de propiedad intelectual.

\section{DISCERNIMIENTO CRÍTICO DE RAZÓN TECNO-PRODUCTIVA}

La idealización de las tendencias tecnoproductivas sintonizaría con propuestas que de forma encubierta promueven la privatización de los bienes públicos y la reducción de las funciones del Estado. Se hace necesario poder distinguir entre la producción de bienes intangibles y nuevas formas de parasitismo rentista, que operan sobre la base de una pseudoriqueza intangible basada en rentas derivadas de la propiedad de bienes inmobiliarios, patrimonios financieros, o desde mercados monopólicos u oligopólicos. Quienes denuncian el "ciberfetichismo» acusan un intento de hacer de las redes telemáticas un limbo jurídico, político y ético, ya que tras la idea de un modo de producción entre pares se podrían envolver nuevas formas de especulación y explotación social. «Las voces que claman por la desregulación de Internet buscarían impedir que se pongan cadenas al Paraíso» (De la Cuesta, 2000) pero la falta de intervención jurídica olvida que el ciberespacio es un complejo campo de relaciones humanas.

La regulación jurídica debe atender el dilema de la liberación de contenidos digitales, cuyas externalidades abarcan desde la divulgación del «arma imprimible 3D», la circulación de monedas virtuales como el bitcoin, el ciberespionaje estatal o privado, los nuevos ciberdelitos, hasta el problema de la justa remuneración de los autores o el financiamiento de costosos proyectos en I+D+i. No es justo, afirma Rendueles, afirmar que «los creadores de copyright viven de una industria obsoleta que el mercado darwiniano se encargará de depurar si se eliminan las regulaciones» (Rendueles, 13 mayo 2013). Las críticas al paradigma $\mathrm{P} 2 \mathrm{p}$ evidencian que la simple orientación al objetivo no basta a la hora de definir la legitimidad social de las actividades económicas, aunque se desarrollen en el ámbito de la producción de bienes comunes intangibles. En palabras de Richard Sennett: 
Es indudable que escuchar con atención y trabajar en armonía con los demás implica un aspecto ético; sin embargo, concebir la cooperación tan sólo como algo positivo desde el punto de vista ético entorpece su comprensión. Así como el buen científico-artesano puede dedicar sus energías a producir la mejor bomba nuclear posible, también se puede colaborar con toda eficiencia en un robo. (Sennett, 2012:10)

Estas perspectivas delimitan las transformaciones en los modelos tecnoproductivos sin caer en los determinismos cientificistas, ni en la fetichización de la tékne digital. La tensión permanente por el acceso a los bienes comunes intangibles, especialmente por la imposición de protocolos de control y regulación de la producción digital, muestra una relación con las dinámicas de los procesos de «acumulación por desposesión» como lo ha descrito Harvey (2004). La analogía con los enclosures parece pertinente en la medida en que estos procesos de clausura muestran formas de privatización de recursos producidos colectivamente, que pueden ser homologados a los que acontecen en el ámbito de los recursos naturales o la fuerza de trabajo. Pero esta comparación debe ser contextualizada, ya que el ámbito digital no constituye per se un espacio en el que la libertad se pueda regir por condiciones o normas diferentes a las del mundo analógico. Como observa Rubén Martínez, pensar que en la esfera de la red «la cooperación se da de manera espontánea es absurdo. Pensar que la tecnología otorga libertad por ciencia infusa es un disparate» (Martínez, 16 mayo 2013). En la actualidad «la arquitectura de la red» se está asemejando a la arquitectura de los espacios físicos y no al revés. Martínez lo ejemplifica en procesos de concentración de poder de forma oligopólica que se valen de la legislación para provocar un «asalto sin regulación de derechos fundamentales de la ciudadanía, explotación de la fuerza de trabajo -gratuita, "voluntaria"-, depredación de los recursos comunes -digitales, naturales, culturales, como guste llamarlos-» (Martínez, 16 mayo 2013). Lo anterior no equivale a afirmar que en las redes digitales no existe, ni puede existir, organización social.

Las redes digitales son bienes comunes intangibles en tanto espacios interactivos, relacionales y comunicativos, que permiten los flujos económicos y productivos. Se encuentran arraigados en marcos culturales y sociales en los que se hayan incrustados. De allí que demanden una forma especial de gobernanza política, regulación legal y consecuentemente una permanente deliberación moral que dé cuenta de sus singularidades. Su gestión y gobierno reclaman una ética pública procedimental que no se asiente en un principio heterónomo y material, basado en criterios de 
orientación al objetivo, sino en un principio formal e incondicionado que tenga pretensiones de validez universal y auto-obligación y basado en la corresponsabilidad (Kant, 2006: 92). La circularidad de la hermenéutica crítica abriría un horizonte de legitimación normativo que, reconociendo el valor de las normas consuetudinarias, las sometería a la criba de la razón crítica, de tal forma que se impida su naturalización, por medio de su confrontación con criterios trascendentales, que permitan tamizar estas costumbres desde un imperativo que consagre a cada interlocutor como un participante válido en sí mismo.

\section{BIBLIOGRAFÍA}

Aglietta, M. (1998): Regulación y crisis del capitalismo. La experiencia de los Estados Unidos, Madrid, Siglo xxI.

Attali, J. (1989): Historia de la Propiedad, Barcelona, Planeta.

Barbrook, R. y A. Cameron (1996): "The californian ideology», Science as Culture, 26, pp. 44-72.

Bauwens, M. (2005): «The Political Economy of Peer Production», Post-Autistic Economics Review 37, [en línea] [http://www.ctheory.net/articles. aspx?id=499], consulta: 23/07/2012.

- (4 marzo 2012) «Peer-to-Peer Relationality», [en línea] [http://blog.p2pfoundation.net/essay-of-the-daypeer-to-peer-relationality/v, 2012/03/04], Consulta: 17/06/2013.

BelL, D. (1976): El advenimiento de la sociedad postindustrial, Madrid, Alianza.

BENKLER, Y. (2006): The wealth of networks: how social production transforms markets and freedom, New Haven, Yale University Press.

BERARDI, F. (2003): La fábrica de la infelicidad. Nuevas formas de trabajo $y$ movimiento global, Madrid,Traficantes de Sueños.

Blondeau, O. y otros (2004): Capitalismo cognitivo, propiedad intelectual $y$ creación colectiva, Madrid,Traficantes de sueños.

BusANICHE, B. y otros (2007): MABI: monopolios artificiales sobre bienes intangibles, Córdoba, Fundación Vía Libre.

CORIAT, B. (1992): Pensar al revés: Trabajo y organización de la empresa japonesa, México, Siglo xxI.

De la Cuesta, P. M. (2000): «Software libre o propietario: Cuestión de Ideas», Boletín del Criptonomicón 79, [en línea] [http://www.iec.csic.es/criptonomicon/articulos/expertos79.html], Consulta: 10/05/2012. 
DRUCKER, P. F. (1968): The age of discontinuity: guidelines to our changing, Nueva York, Harper \& Row Society.

Gutiérrez-Rubí, A. y J. Freire, eds. (2013): Manifiesto Crowd, Laboratorio de tendencias, Kindle e-book.

Galbraith, J. K. (1986): El nuevo estado industrial, Barcelona, Planeta-Agostini.

Gorz, A. (7 enero 2008) «Le travail dans la sortie du capitalisme», Revue critique d'écologie politique 28, [en línea] [http://ecorev.org/spip. php?article641], consulta: 3/03/2012.

HARDt, M. y Negri, A. (2011): Commonwealt, Madrid,Akal.

HARVEY, D. (2004) El nuevo imperialismo, Madrid, Akal.

Helfrich, S. ed. (2008) Genes, bytes y emisiones: Bienes comunes y ciudadanía, Fundación Heinrich Böll Latinoamérica.

Huws, U. (2003): The Making of a Cybertariat. Virtual Work in a Real World, Nueva York, Monthly Review Pess.

Kant, I. (2006): La paz perpetua. Traducción de J.Abellán, Madrid,Alianza.

KELLY, K. (1998): New Rules for the New Economy. 10 radical strategies for a connected world, Nueva York, Viking Pinguin.

LEBERT, D. y VerCellone, C. (2010): « Les rapports entre capitalisme cognitif et capitalisme mafieux», Tina, 6, Centre d'économie de la Sorbonne (CES) pp.74-80.

Lessig, L. (2006): El código 2.o, Madrid,Traficantes de sueños.

MaCPherson, C. (2005): La teoría política del individualismo posesivo. De Hobbes a Locke, Madrid, Trotta.

Martínez, R. (16 mayo 2013): «La ilusión de los bienes comunes. Cierto, pero...» [en línea] [http://leyseca.net/la-ilusion-de-los-bienes-comunescierto-pero], consulta: 5/05/2012.

MARX, K. (1967): Formaciones económicas precapitalistas, México,Talleres Gráficos.

MASUdA, Y. (1984): La sociedad informatizada como sociedad post-industrial, Madrid, Fundesco-Tecnos.

Mattelart, A. (1974): La cultura como empresa multinacional. Buenos Aires, Galerna.

Morozov, E. (2012): El desengaño de internet: los mitos de la libertad en la red. Traducción de Eduardo G. Murillo, Barcelona, Destino.

National Intelligence Council (2012): Global Trends 2030: Alternative Worlds, Seattle, Create Space Independent Publishing Platform. 
Ostrom, E. (2002): "The evolution of norms within institutions: comments on Paul R. Ehrlich and Anne H. Ehrlich's», Environment and Development Economics, 7 (01), pp. 171-190.

PEKKa, H. y otros (2002): La ética del backer y el espíritu de la era de la información, Barcelona, Destino.

PÉrez, C. (2002): Technological Revolutions and Financial Capital: The Dynamics of Bubbles and Golden Ages, Londres, Elgar.

POLANYI, K. (1989): La gran transformación, Madrid, La Piqueta.

ReNdueles, C. (13 mayo 2013): «La ilusión de los bienes comunes», [en línea] [http://espejismosdigitales.wordpress.com/2013/05/13/la-ilusion-delos-bienes-comunes], consulta: 12/07/2013.

Rheingold, H. (2002): Multitudes inteligentes. La próxima revolución social, Barcelona, Gedisa.

RICCI, R. y C. WIESE (2011): Collaboration Imperative Executive Strategies for Unlocking Your Organization's True Potentia, San José, California, Cisco Systems.

SÁDABA, I. (2008): Propiedad intelectual ¿Bienes públicos o mercancías privadas?, Madrid, Catarata.

SENNET, R. (2012):Juntos. Rituales, placeres y política de cooperación. Traducción Marco Aurelio Galmarini, Barcelona, Anagrama.

Stallman, R. (Marzo 1985): «GNU manifesto», Dr. Dobb's Journal of Software Tools, Dr. Dobb's Journal 10 (3): 30. [http://www.gnu.org/gnu/manifesto.html], consulta: 10-09-2012.

TOFfler,A. (1973): El shock del futuro, Barcelona, Plaza \& Janés [Traducción de J. Ferrer Aleu].

Touraine, A. (1969): La sociedad post-industrial, Barcelona, Ariel [Traducción de Juan-Ramón Capella y Francisco J. Fernández Buey].

Thomas, H. y A. Vercelli (2008): «Repensando los bienes comunes: análisis socio-técnico sobre la construcción y regulación de los bienes comunes». Sci. stud. vol. 6 3, São Paulo [http://dx.doi.org/10.1590/S167831662008000300010], consulta: 04/05/2013.

VIRNO, P. (2003a): Virtuosismo y revolución. Notas sobre la acción política en la era del desencanto, Madrid, Traficantes de Sueños.

- (2003b): Gramática de la multitud. Para un análisis de las formas de vida contemporáneas, Madrid, Traficantes de sueños. 